\title{
A PROPOSTA DE REDAÇÃO DO VESTIBULAR DA UNIOESTE: UMA EXPERIÊNCIA EDUCATIVA E DE SOCIALIZAÇÃO ${ }^{1}$
}

\author{
Marcia Sipavicius Seide \\ Universidade Estadual do Oeste do Paraná \\ marciaseda4@hotmail.com \\ Rita Maria Decarli Bottega \\ Universidade Estadual do Oeste do Paraná \\ ribottega@uol.com.br \\ Elisangela Redel \\ Universidade Estadual do Oeste do Paraná \\ lizaredel@gmail.com
}

\author{
Franciele Maria Martiny \\ Universidade Estadual do Oeste do Paraná \\ franmartiny@hotmail.com \\ Patrícia Frai \\ Universidade Estadual do Oeste do Paraná \\ patriciafrai@hotmail.com \\ Gabriela Lauermann \\ Universidade Estadual do Oeste do Paraná \\ gabi.lauermann@hotmail.com \\ Fernanda Maria Muller Gehring \\ Universidade Estadual do Oeste do Paraná \\ fermullergehring@hotmail.com
}

\begin{abstract}
Resumo
O objetivo deste trabalho é descrever e analisar a atividade de extensão universitária intitulada "A proposta de redação do vestibular da Unioeste: características e critérios de correção", promovida pelo Colegiado de Letras, de Marechal Cândido Rondon (PR), no $2^{\circ}$ semestre de 2014, destinado a alunos do Ensino Médio (sede e distritos). A iniciativa objetivou contribuir para um melhor entendimento da proposta de redação referente ao Processo Seletivo de Vestibular da citada Universidade e dos critérios de correção adotados pela Banca Corretora. Para tanto, a metodologia foi constituída por uma prática docente organizada em três módulos que contemplaram, respectivamente: a) características definidoras dos gêneros discursivos solicitados nas propostas de redação (carta do leitor, artigo de opinião e comentário interpretativo-crítico); b) leitura e análise das propostas de redação do último vestibular (2014) e explicitação dos critérios de correção utilizados; c) sistemática de correção, critérios de avaliação e análise de redações corrigidas pela Banca de Correção.

Palavras-chave: Relato de Experiência. Ensino. Língua Portuguesa. Redação do Vestibular da Unioeste.
\end{abstract}

\section{THE COMPOSITION WRITTEN TEST OF UNIOESTE COLLEGE ENTRANCE EXAM: AN EDUCATIONAL AND SOCIALIZATION EXPERIENCE}

\begin{abstract}
This work aims to describe and analyse the activity of the university extension program named: "The composition written test of Unioeste college entrance exam: correction characteristics and criteria", which was constituted on the implementation of a university extension activity promoted by the Language Collegiate, from Marechal Cândido Rondon, in the 2nd semester of 2014, destined to students of Highschool (city and districts). The initiative aimed to contribute for a better understanding of the composition test related to the Admittance Process (known in Brazil as Vestibular) of the cited university and the criteria adopted by the Examination Board. The methodology was constituted by a teaching practice organized in three stages which included, respectively: a) defining characteristics of discursive genre requested in the composition proposals (reader's letter, article of opinion and interpretative-critical comment); b) reading and analysis of the last vestibular (2014) composition tests and explanation of correction criteria used; c) systematic correction, evaluation criteria and analysis of compositions corrected by the Examination Board.
\end{abstract}

Keywords: Experience Report. Teaching. Portuguese Language. Vestibular composition at Unioeste.

\footnotetext{
${ }^{1}$ Uma versão reduzida deste texto foi publicada em: Resultados da atividade extensionista sobre avaliação da prova de redação da Unioeste: características e critérios de correção. In: XV Seminário de Extensão da UNIOESTE, 2015, Marechal Cândido Rondon. XV Seminário de Extensão da Unioeste: interfaces e novas perspectivas. Cascavel: Edunioeste, 2015. v. 1. p. 912-918.
} 


\title{
LA PROPUESTA DE REDACCIÓN DE VESTIBULAR DE LA UNIOESTE: UNA EXPERIENCIA EDUCATIVA Y DE SOCIALIZACIÓN
}

\begin{abstract}
Resumen
El objetivo del trabajo es describir y analizar la actividad de extensión universitaria que lleva el título "La propuesta de redacción de la selectividad de Unioeste: características y criterios de corrección”, promovida por el Colegiado de Letras, de Marechal Cândido Rondon (PR), en el según semestre de 2014, destinado a alumnos de la enseñanza secundaria (sede y comarcas). La iniciativa objetivó contribuir para un mejor entendimiento de la propuesta de redacción referente al Proceso Selectivo de la Selectividad de la citada Universidad y de los criterios de corrección adoptados por el Tribunal de Corrección. Para tanto, la metodología fue constituida por una práctica docente organizada en tres módulos, que contemplaron, respectivamente: a) características definidoras de los géneros discursivos solicitados en las propuestas de redacción (carta del lector, artículo de opinión y comentario interpretativo-critico); b) lectura y análisis de las propuestas de redacción de la última selectividad (2014) y explicitación de los criterios de corrección utilizados; c) sistemática de corrección, criterios de evaluación y análisis de redacciones corregidas por el Tribunal de Corrección.

Palabras clave: Relato de Experiencia. Enseñanza. Lengua Portuguesa. Redacción de la Selectividad de Unioeste.
\end{abstract}


A proposta de redação do vestibular da Unioeste: uma experiência educativa e de socialização

\section{INTRODUÇÃO}

A necessidade de propor um curso de extensão que abrangesse a redação do vestibular da Unioeste se deu a partir de constatações de algumas professoras que compõem a banca corretora. Estas perceberam, ao corrigirem as redações dos vestibulandos, além de outros fatores, a falta de domínio dos gêneros discursivos. Conforme as corretoras, por exemplo, a grande maioria dos candidatos escrevia a famosa "dissertação escolar", e não o gênero discursivo textual que era solicitado na prova de redação; percebeu-se que os vestibulandos até reconheciam os gêneros (carta do leitor e artigo de opinião - os mais frequentes neste concurso) como pertencentes à tipologia argumentativa, mas as principais características do gênero eram desconhecidas, o que ficava evidente nas notas das redações.

No cenário brasileiro, as pesquisas voltadas às teorias de gêneros, textuais e discursivos, surgiram na década de 1990, momento em que também se iniciam as discussões e a formulação dos Parâmetros Curriculares Nacionais para o ensino de Língua Portuguesa (PCNs).

Neles são ressaltados os estudos de Mikhail Bakhtin, para quem a noção de gênero do discurso está presente em todas as esferas da atividade humana, as quais, por sua vez, estão relacionadas à utilização da língua por meio da criação de enunciados, tanto orais quanto escritos. Esses enunciados refletem os objetivos e as condições de cada esfera, bem como o seu conteúdo, sua construção composicional e um determinado estilo de linguagem. Para o autor, "qualquer enunciado considerado isoladamente é, claro, individual, mas cada esfera de utilização da língua elabora seus tipos relativamente estáveis de enunciados, sendo isso que denominamos gêneros do discurso" (BAKHTIN, 2000, p. 279). As DCEs também defendem que a aprendizagem de língua portuguesa foque o texto e a interação social de práticas discursivas e inclua questões de uso, contextuais, valorizando o texto como unidade fundamental de análise (PARANÁ, 2008, p. 17).

A proposta de redação da Unioeste se baseia nesse mesmo norteamento conceitual: os critérios de avaliação não abrangem apenas a adequação à norma padrão escrita, mas também os aspectos relacionados aos gêneros. Estes aspectos incluem a situação social de produção (com a observação da temática, adequação à interlocução, a organização composicional do gênero escolhido, o estilo de linguagem, a recepção e a circulação, tendo em vista a situação social em que o gênero está inserido), além da observância aos aspectos textuais (como a necessidade de produção de um texto coeso e coerente e com itens lexicais adequados ao gênero, ao registro e ao assunto). Nesse sentido, são levados em consideração aspectos relacionados à Linguística Textual, (KOCH,2009a, 2009b), e concebe-se o texto como um constructo social. Por extensão, na produção textual, o aluno deve estar consciente de que, na elaboração de sua redação, há "um 
trabalho na escolha de utilização dos recursos linguísticos que permitem melhor viabilizar a intenção comunicativa que se tem" (KOCH, 2009a, p. 106).

Com base nisso, a proposta de redação da Unioeste leva em consideração a necessidade de a produção textual estar situada em contextos reais de interação comunicativa, além de apresentar marcas de textualidade. Elas se referem aos critérios de textualidade de coerência textual (a articulação, a não contradição, a progressão, a continuidade temática, entre outros) e à coesão textual (promovida pela utilização dos mecanismos de coesão referencial pronominal e sequencial ou conjuntiva), vistos como dependentes da situação social de produção proposta.

Portanto, os critérios de textualidade permitem a articulação de todas as partes do texto, para que se forme um todo coerente e coeso, e não apenas um amontoado de frases. Sendo assim, o aluno deve apresentar um repertório diversificado de recursos linguísticos, juntamente com a adequação ao gênero, uma vez que a coerência passa a ser "entendida como a configuração conceitual subjacente e responsável pelo sentido do texto, e a coesão como sua expressão no plano linguístico" (COSTA VAL, 2016, p. 20).

Sob o viés teórico acima apresentado, a prova de redação da Universidade Estadual do Oeste do Paraná (Unioeste) - a qual desde 2013 passou a também adotar o SISU como forma de ingresso na instituição - está centrada na capacidade de o aluno interagir com o outro, organizar as ideias, estabelecer relações, argumentar e interpretar dados e fatos por meio de excertos disponibilizados na proposta, a partir de uma situação interativa mediada pelo gênero, enfoques que foram enfatizados na realização do projeto.

Feitas estas considerações iniciais, primeiramente são apresentados os objetivos da extensão intitulada "A proposta de redação do vestibular da Unioeste: características e critérios de correção", a sua organização, os meios de divulgação e inscrição, bem como a equipe que organizou os trabalhos. Em um segundo momento, são descritos os módulos que compuseram o curso. $\mathrm{Na}$ sequência, há relatos das professoras envolvidas nesta experiência educativa. Finalizando o artigo, são feitas as considerações finais. Cumpre informar que não houve atividades de produção textual por parte dos alunos, motivo pelo qual não há evidências sobre o impacto do curso em seu desempenho textual.

\section{MATERIAIS E MÉTODOS}

Foi formado um grupo de professoras e alunas da pós-graduação, com formação acadêmica na área de Letras, para ministrar um curso na tentativa de sanar os problemas 
apontados por corretoras da banca de redação. A coordenação do curso ficou a cargo de duas professoras, que integram a banca de correção da redação do concurso vestibular da Unioeste há mais de dez edições. Essas professoras orientaram a equipe em reuniões antes e durante o desenvolvimento do curso, o que contribuiu ativamente para a elaboração do material didático e para o planejamento das aulas. Importa ressaltar que a equipe de trabalho reuniu egressos do curso de Letras da Unioeste, de Marechal Cândido Rondon, proporcionando-lhes uma vivência genuína e significativa em atividades extensionistas o que, certamente, despertou-lhes o interesse pela Extensão Universitária e a percepção de sua contribuição na sociedade mais ampla de que faz parte.

A base teórica utilizada para a formulação do Projeto foi a mesma utilizada pela Banca de Correção, a saber: para coesão textual, utilizaram-se os estudos de Koch (2009b), para coerência textual, os estudos de Costa Val (2006) e também Koch (2009a), e para a delimitação e caracterização dos gêneros discursivos utilizou-se o que propõem as Diretrizes Curriculares da Educação Básica do Estado do Paraná (2008). Até o vestibular de 2011, os critérios de correção da Banca estavam baseados nos pressupostos da Linguística Textual, perspectiva teórica ampliada desde o vestibular de 2012, momento em que a comissão decidiu contemplar, também, a abordagem dos gêneros discursivos, visto que a leitura e produção textual levam em conta não apenas a tipologia textual, mas, principalmente, sua função sociocomunicativa (BAKHTIN, 1990; 2000).

Nas reuniões da equipe extensionista, decidiu-se que, além da sede do câmpus da Unioeste de Marechal Cândido Rondon, aconteceriam visitas aos estabelecimentos de ensino dos distritos rondonenses de Iguiporã e Margarida, e a Novo Sarandi (distrito do município de Toledo), além do município de Pato Bragado, visto que estes ainda não tinham sido foco de nenhuma atividade extensionista vinculada ao Curso de Letras da Unioeste, câmpus de Marechal Cândido Rondon. A divulgação foi realizada de forma presencial - com distribuição de panfletos e cartazes explicativos contendo as principais informações do curso - e por meio de mídias eletrônicas e redes sociais. As escolas da região também foram comunicadas sobre o curso por meio de e-mail e, paralelamente, foi criada uma página do projeto no facebook. Inscreveram-se 224 pessoas para as 63 vagas ofertadas. Do total de interessados, 85 eram alunos de escolas públicas de Marechal Cândido Rondon, 81 das escolas públicas dos distritos, 37 de escolas particulares da mesma cidade e 21 interessados que já tinham concluído o Ensino Médio.

Após a divulgação e a imediata adesão dos alunos, o curso aconteceu durante o mês de setembro de 2014. Os discentes foram distribuídos em três turmas (A, B e C) e em três turnos (manhã, tarde e noite). No período matutino, o curso foi ministrado por duas integrantes do 
grupo e nos períodos vespertino e noturno, por outras três. A carga horária de cada turma foi organizada em 03 (três) módulos, cada um com 4 (quatro) horas, totalizando 12 (doze) horas de curso.

Posterior à oferta e à realização do curso, haja vista a demanda de inscritos ter sido maior do que a oferta de vagas, foi realizada uma palestra sobre a proposta de redação do vestibular da Unioeste, no período noturno, no câmpus universitário, a fim de atender parte dos alunos que não haviam conseguido vagas. Compareceram a esta palestra cerca de 50 alunos do Colégio Estadual Antônio Maximiliano Ceretta, encaminhados à universidade por uma professora de Língua Portuguesa do citado colégio. Cada módulo do curso ficou organizado da seguinte forma:

a) Módulo I: leitura e análise das propostas de redação do concurso de vestibular da Unioeste de 2014 e explicitação dos critérios de correção utilizados, bem como informações sobre a composição da Banca Permanente de Correção das Redações do supracitado vestibular (banca composta por professores da Unioeste e da rede pública de ensino da região, abrangendo todos os câmpus da universidade) e a organização dos trabalhos de correção (que abrange o sigilo e a sistemática de correção das redações por dois corretores, sendo que um não sabe a nota dada pelo outro; a leitura do texto por um terceiro corretor, quando necessário; e a correção pelas mesmas duplas dos alunos candidatos ao mesmo curso).

b) Módulo II: características definidoras dos gêneros discursivos que são solicitados nas propostas de redação (carta do leitor, artigo de opinião e comentário interpretativo-crítico, sendo que, a cada ano, dois desses gêneros são contemplados nas propostas do vestibular e cabe ao candidato escolher um deles para desenvolver a sua produção textual). Para tanto, houve atividades de leitura, interpretação e discussão de exemplares de cada gênero discursivo; essas atividades tiveram por finalidade expor, na prática, a presença dos elementos vinculados a determinado gênero textual.

c) Módulo III: sistemática de correção, critérios de avaliação e análise de redações corrigidas pela Banca de Correção, tendo como base a tabela de critérios utilizada pela banca corretora do vestibular. No terceiro módulo, os alunos foram motivados a aplicar os critérios de correção em outras redações, cuja correção foi avaliada e comentada, tendo por parâmetro as notas que foram realmente atribuídas a cada redação pela banca. Cumpre esclarecer que foi mantido o sigilo dos escritores, uma vez que só foi informado o número de identificação de cada redação.

Acredita-se que o ponto mais favorável dos três módulos tenha sido a apresentação dos gêneros textuais discursivos (por parte das professoras) e o conhecimento/entendimento por parte dos alunos. A falta de contato com o gênero e/ou o seu não conhecimento fazem com que 
os alunos tenham dificuldade e até sejam impossibilitados de escrevê-lo. Por isso, é importante reconhecer o gênero textual (e não mais a dissertação escolar) como prática social (BAKHTIN, 1990, 2000), tendo em vista, entre outros aspectos, a estrutura composicional, o estilo e o conteúdo temático correspondentes a cada gênero.

\section{RESULTADOS E ANÁLISES}

Conforme já citado, no período da manhã (turma A), as aulas foram ministradas por duas professoras e, no período da tarde e da noite (turmas B e C, respectivamente), por outras três. $\mathrm{Na}$ sequência, podem ser observados os relatos das experiências de cada grupo, em cada uma das três turmas.

\section{Resultados de experiência: Turma A}

Durante a realização da atividade de extensão no período matutino, surgiu uma problemática não esperada: o não comparecimento de alunos inscritos nesta turma e a baixa frequência de outros. Ressalta-se, contudo, que os demais alunos deste módulo foram assíduos: cumpriram o horário (logo cedo de manhã já estavam presentes, ou seja, às 7 h30min) e participavam, mesmo que de forma tímida, das diversas atividades propostas. No primeiro encontro, 14 alunos compareceram e, no segundo, somente 9 alunos estavam presentes.

Possivelmente, o que contribuiu para o acanhamento dos alunos foi o fato de o grupo ter sido bastante heterogêneo, composto por pessoas de escolas particulares, estaduais e da própria universidade. Outro fator a ser destacado é que os alunos provenientes do interior do município, Porto Mendes e Iguiporã, demonstravam participação menor do que a da outra metade, constituída por alunos de escolas da sede. Percebeu-se certo constrangimento por parte dos alunos das escolas do ambiente rural, o que pode ter impedido sua interação e participação no grupo. Pode ser que esse constrangimento tenha por origem o estereótipo de que as escolas públicas são inferiores às particulares, ou de que as escolas do interior são mais “atrasadas" que as da cidade.

Outro aspecto a ser mencionado é que, desde o início, os alunos mostraram grandes dificuldades com relação aos gêneros artigo de opinião, carta do leitor e comentário interpretativo-crítico. Durante a experiência educativa, não demonstraram ter muito conhecimento prévio sobre o que estava sendo trabalhado nos encontros. A mesma dificuldade dos alunos foi notada no que concerne à coerência e coesão textual e à tipologia argumentativa, sobre as quais pareciam quase não ter domínio. Pôde-se observar isso durante as atividades de 
análise textual de redações já produzidas, as quais causaram muitas dúvidas nos participantes, que tinham, em sua maioria, até dificuldades em compreender as diferenças entre questões de coerência e de coesão textuais, com ênfase nos problemas relacionados à progressão e à sequenciação textuais.

Estas constatações podem ser indícios indiretos de que, nas escolas, esse conteúdo não tem sido visto ou tem sido pouco explorado, o que também remete para possíveis dificuldades que os professores de Língua Portuguesa têm com estes conteúdos na sua formação inicial e, depois, na formação continuada. Esta problemática mostra que há necessidade de atividades extensionistas serem ofertadas às escolas, diminuindo a distância entre elas e a universidade. Com relação à argumentatividade, recorrentemente, verificou-se o uso do senso comum nas tentativas de argumentação dos participantes, mostrando, muitas vezes, a falta de leitura sobre os temas das propostas de redação.

Quanto ao entendimento dos gêneros solicitados na proposta de vestibular da Unioeste, os participantes desta turma mostraram um pouco de conhecimento em torno da carta do leitor e do artigo de opinião, que já foram trabalhados, segundo eles, na escola; porém, ainda apresentaram dúvidas em relação às suas estruturas e circulação nas esferas sociais. Já o comentário interpretativo-crítico era totalmente desconhecido pelos alunos.

Outra questão que chamou a atenção da equipe foi o questionamento de muitos participantes sobre como usar os textos-base contidos nas propostas na produção da redação, demonstrando preocupação em relação ao plágio.

Ao final do curso, os alunos desta turma avaliaram o projeto e disseram estar muito satisfeitos com o que foi visto, que tudo era muito novo e que já estariam melhor preparados para o vestibular do que antes. Ao mesmo tempo, sinalizaram que o tempo destinado para os alunos, ou seja, apenas três encontros, foi insuficiente. Eles gostariam que o curso fosse estendido, que tivesse um número maior de encontros e com maior ênfase na produção textual dos gêneros analisados.

\section{Resultados de experiência: Turmas B e C}

Como o curso foi ministrado pelas mesmas professoras, o relato das turmas B e C é feito concomitantemente neste trabalho.

Diferentemente do ocorrido na turma A, as turmas B e C tiveram poucas desistências. Em geral, os alunos foram frequentes, fato que pode ter relação com a certificação fornecida, ao final do curso, a quem tivesse assiduidade. Ademais, alunos que não haviam recebido a confirmação de que participariam do curso vieram e foram incluídos na lista de alunos inscritos. 
Com relação à procedência dos estudantes, a turma $\mathrm{B}$ era composta por alunos oriundos, cerca de $60 \%$, das escolas particulares e o restante dos colégios públicos, todos provenientes do município sede do projeto. Já a turma $C$ era formada, predominantemente, por estudantes da rede pública de ensino, oriundos do município sede e das localidades próximas. Em geral, os estudantes das escolas privadas eram mais participativos e mostravam ter conhecimento dos temas abordados. Em contrapartida, também mostraram desatenção em vários momentos.

Dentre os assuntos abordados, alguns chamaram mais atenção e foram mais questionados pelos estudantes. Um deles foi uma característica específica que diferencia os gêneros artigo de opinião e dissertação escolar: o primeiro, diferente do segundo, não precisa ser encerrado com uma proposta de solução para o tema/assunto tratado no texto, fato desconhecido por uma parte considerável dos estudantes - principalmente os estudantes da rede pública - e que evidencia uma lacuna no ensino deste gênero nas escolas, mostrando, mais uma vez, a necessidade de mais ações que focalizem a produção textual na formação continuada para os docentes e cursos nesse sentido para os discentes.

Com relação às demais características dos três gêneros solicitados na proposta do vestibular, percebeu-se que os alunos sabiam que se tratava de uma tipologia argumentativa, no entanto, não conheciam como se dava a circulação dos gêneros, nem a que esferas de atividade humana estavam relacionados. Também ignoravam o dialogismo que os constitui, questões inerentes para a compreensão global do gênero e, em decorrência, para uma melhor escrita do texto, o que justamente diferencia a produção textual efetiva de gêneros e não mais de tipologias. Constata-se que, apesar de já haver essa nova concepção de ensino nos próprios documentos norteadores, pouco se tem trabalhado em sala de aula, permanecendo ainda uma atenção maior às questões gramaticais ou até mesmo trazendo o gênero, mas de forma ainda superficial, apenas focalizando aspectos de sua estrutura composicional.

Com relação a esse último ponto, o gênero carta argumentativa foi mais questionado com relação à sua estrutura. Também questões sobre linhas em branco, assinatura, data e vocativo foram recorrentes, o que na verdade exige apenas um esclarecimento básico, não um trabalho mais profundo como seria com as questões dialógicas.

O gênero comentário interpretativo-crítico foi recebido com estranheza pelos alunos, a exemplo do que ocorreu com a turma A. Provavelmente muitos deles nunca sequer ouviram falar do mencionado gênero e há pouco material sobre isso na internet e em livros didáticos comumente usados nas escolas. Como este gênero não havia sido proposto em concurso de vestibular da Unioeste até então, foi utilizado um exemplo de atividade de aula de Língua Portuguesa para que os alunos tivessem contato com o gênero. 
As atividades relacionadas ao estudo, análise e compreensão das propostas de redação revelaram que algumas dificuldades são sentidas por todos os estudantes, estudem ou não em escolas públicas, sejam elas sediadas no distrito ou na sede do município. Além da dificuldade de entendimento, por alguns deles, do tema/assunto a ser abordado, percebeu-se falta de domínio e entendimento de conceitos relativos à ideologia, ao capitalismo e ao consumismo, tópicos que se espera façam parte do ensino das disciplinas relacionadas com as humanidades: Filosofia, Sociologia, História e Geografia. Ressalta-se que a má compreensão desses tópicos pode comprometer a redação do vestibulando, pois se ligam diretamente ao texto que este aluno escreverá, uma vez que esses conceitos não são explicados nas propostas, havendo a pressuposição de que o aluno os saiba, o que revela a natureza interdisciplinar da proposta de redação do vestibular da Unioeste.

O curso possibilitou também que os estudantes pudessem ler redações elaboradas por candidatos no ano anterior, mediante leitura coletiva, durante a qual foram apontados os aspectos fortes e fracos dos textos com base em textos que tiveram nota baixa, média e alta. Sendo assim, questões como coerência e coesão puderam ser percebidas pelos próprios alunos, assim como as demais questões relacionadas à textualidade. Esse exercício propiciou uma autoavaliação dos estudantes, que puderam compreender e apontar as lacunas encontradas. Também lhes foi possível perceber estratégias argumentativas e discursivas bem sucedidas numa redação com nota alta.

\section{CONSIDERAÇÕES FINAIS}

Haja vista os relatos apresentados, o ponto mais favorável dos três módulos foi a apresentação dos gêneros textuais discursivos (por parte das professoras) e o seu conhecimento/entendimento por parte dos alunos. A falta de contato com o gênero e/ou o seu não conhecimento fazem com que os alunos tenham dificuldade e até sejam impossibilitados de escrevê-lo. Por isso, é importante reconhecer o gênero textual (e não mais a dissertação escolar) como prática social (BAKHTIN, 1990, 2000), tendo em vista, entre outros aspectos, a estrutura composicional, o estilo e o conteúdo temático correspondente a cada gênero. Além disso, outra constatação da equipe foi a de que, enquanto os alunos provenientes de escolas particulares pareceram estar mais familiarizados com o gênero discursivo artigo de opinião, os discentes da rede pública pareciam não ter tido acesso à informação sobre este gênero ou ainda confundiamno com um texto dissertativo-argumentativo. Já o gênero comentário interpretativo-crítico era 
desconhecido por praticamente todos os alunos participantes, exigindo uma atenção maior no curso. Os participantes, de forma geral, demonstraram pouco ou, em alguns casos, nenhum conhecimento prévio sobre elementos de coesão e de coerência, mas dominam alguns recursos e outros não. Evidenciaram, por exemplo, maiores dificuldades nos aspectos relacionados com a coesão sequencial, e mais facilidade com a coesão referencial. As hipóteses da banca de correção justificadoras da realização da atividade de extensão confirmaram-se, revelando que a avaliação das redações do vestibular também pode fornecer indícios sobre o ensino de língua portuguesa na região.

Acredita-se que, do ponto de vista dos alunos, a oferta desse curso tenha contribuído para um melhor entendimento da proposta de redação do Vestibular da Unioeste e um aperfeiçoamento da capacidade de autoavaliação da própria redação; do ponto de vista da equipe extensionista, a sua realização propiciou a interação com os alunos, durante o desenvolvimento do curso, e forneceu à equipe valiosas informações sobre o ensino-aprendizagem de produção textual escrita no Ensino Médio na região, mostrando várias lacunas que precisam ainda ser trabalhadas nas aulas de Língua Portuguesa.

Visando atingir o público docente - pois entende-se que sua interferência incidirá positivamente sobre um grande número de alunos - em 2016, os integrantes da Comissão Permanente de Correção de Redação do Vestibular, do campus de MCR, ofertaram aos professores de Língua Portuguesa da rede pública de ensino do Estado, lotados em colégios da cidade de MCR e microrregião e pertencentes ao Núcleo Regional de Educação de Toledo (NRE), o curso "Proposta e critérios de correção da redação do vestibular da Unioeste: teoria e práxis", com quatro encontros, em caráter de minicursos, sobre os critérios de correção da redação, simulações de correções de redações de vestibulares anteriores (com comparação de escores atribuídos), bem como o aprimoramento teórico do docente, em relação ao aporte teórico específico que dá sustentação aos critérios de correção.

Ambos os projetos foram relevantes: ampliaram a atuação da Unioeste na comunidade regional, permitiram maior entrosamento entre os membros das equipes extensionistas, fortaleceram o diálogo entre escola, comunidade e universidade e contribuíram, assim, para a formação de todos.

\section{REFERÊNCIAS}

BAKHTIN, M. Marxismo e filosofia da linguagem. São Paulo: Hucitec, 1990. 
A proposta de redação do vestibular da Unioeste: uma experiência educativa e de socialização

Estética da criação verbal. Trad. Maria E. Galvão e revisão por Marina Appenzeller. 3. ed. São Paulo: Martins Fontes, 2000.

BRASIL. Secretaria de Educação Fundamental. Parâmetros Curriculares Nacionais: terceiro e quarto ciclos do Ensino Fundamental: Introdução aos Parâmetros Curriculares Nacionais / Secretaria de Educação Fundamental. Vol. 1. Brasília: MEC/SEF, 1998.

COSTA VAL, Maria da Graça. Redação e textualidade. 4. ed. São Paulo: Martins Fontes, 2016.

KOCH, Ingedore Villaça. A coerência textual. 17. ed. $3^{\circ}$ reimp. São Paulo: Contexto, 2009a.

A coesão textual. 21. ed. $3^{\circ}$ reimp. São Paulo: Contexto, 2009b.

PARANÁ. Diretrizes curriculares da educação básica. Curitiba: MEC, 2008.

SEIDE, Márcia Sipavicius et al. Resultados da atividade extensionista sobre avaliação da prova de redação da Unioeste: características e critérios de correção. In: XV Seminário de Extensão da UNIOESTE, 2015, Marechal Cândido Rondon. XV Seminário de Extensão da Unioeste: interfaces e novas perspectivas. Cascavel: Edunioeste, 2015. v. 1. p. 912-918. 